\title{
Analgesic and Anti-Inflammatory Effects of Hydroalcoholic Extract of Salvia multicaulis on Male Rats
}

\author{
Abdolmaleki A. ${ }^{1}$ MSc, Fereidoni M.* PhD, Farhadi Moghadam B. ${ }^{1}$ MSc, Asgari A. ${ }^{2}$ MSc \\ *Biology Department, Sciences Faculty, Ferdowsi University of Mashhad, Mashhad, Iran \\ ${ }^{1}$ Biology Department, Sciences Faculty, Ferdowsi University of Mashhad, Mashhad, Iran \\ ${ }^{2}$ Agronomy Department, Agriculture Faculty, Ferdowsi University of Mashhad, Mashhad, Iran
}

\begin{abstract} hydroalcoholic extract. repeated measuring and $\mathrm{T}$ student tests. inflammation $(\mathrm{p}<0.01)$. Salvia multicaulis has analgesic effects.

\section{Keywords}

Rats [http://www.ncbi.nlm.nih.gov/mesh/68051381];

Inflammation [http://www.ncbi.nlm.nih.gov/mesh/68007249];

Pain [http://www.ncbi.nlm.nih.gov/mesh/68010146];

Analgesics [http://www.ncbi.nlm.nih.gov/mesh/68000700]
\end{abstract}

Aims: One of the most basic methods for coping with diseases and pain relief had been the use of medicinal plants. The aim of this study was to the determination of analgesic and anti-inflammatory effects of Salvia multicaulis

Materials \& Methods: In this experimental study, 42 male Wistar rats were divided in 6 groups $(n=7)$; the control (receive nothing), the sham (receive solvent intraperitoneally) and 4 groups that received plant extract at the doses of $50,100,200$ and $400 \mathrm{mg} / \mathrm{kg}$ intraperitoneally. Tail flick and formalin test were used for evaluation of thermal and chemical pain, also for assessment the degree of inflammation, rat paw edema volume was acquired by plethysmometric test. Data were analyzed in SPSS 16 software by ANOVA with

Findings: The intraperitoneally injection of extract in all doses decreased the chemical pain induced by formalin $(\mathrm{p}<0.05)$. Hydroalcoholic extract of plant at doses 200 and $400 \mathrm{mg} / \mathrm{kg}$ caused hyperalgesia in compared with control group $(p<0.01)$. All concentrations of hydroalcoholic extract of plant decreased the

Conclusion: Intraperitoneally administration of hydroalcoholic extract of

\footnotetext{
* Corresponding Author

Tel: +985136214026

Fax: +985138762227

Address: Department of Biology, Faculty of Sciences, Ferdowsi University of Mashhad, Vakilabad Highway, Mashhad, Iran. Postal Code: 9177948974

fereidoni@um.ac.ir

Received: January 18, $2015 \quad$ Accepted: May 3, 2015 ePublished: June 20, 2015
} 
آسيب بافتى است. همجنين درد مكانيزمى حفاظتى است و هنكامى

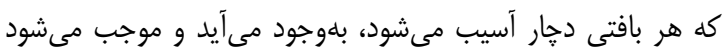

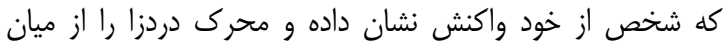

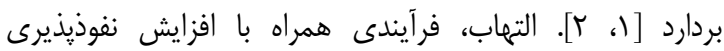

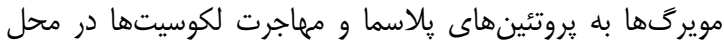

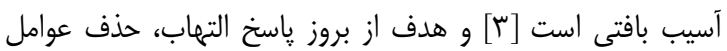
آسيبرسان و ترميم بافتهاى آسيبديده است. مصرف دارئ داروهاى

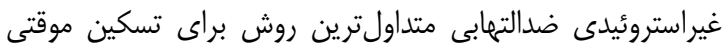

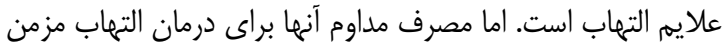

با عوارض جانبى شديدى همراه است [عاب. با توجه به عوارض زياد ناشى از مصرف داروهاى شيميايى، امروزه

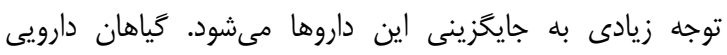

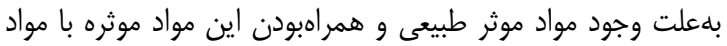

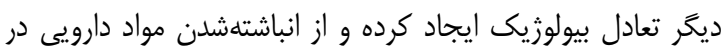

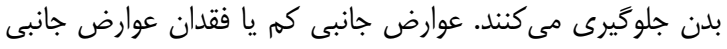

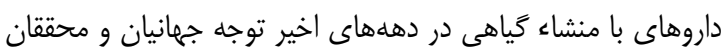
را به اين داروها جلب كرده است و يكى از هدف دارهاى دارئ محققان

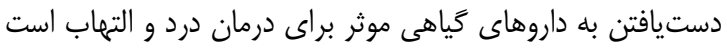
كه عوارض جانبى نداشته باشد [ه].

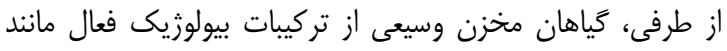
مواد ضددردى، ضدالتهابى، ضدديابتى، ضدسر طانى، آنتىاكسيدانى و و

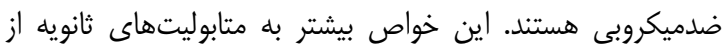
جمله يلىفنولها، فلاونوئيدها، آلكالوئيدها، ترينوئيدها، كاروتنوئئيدها،

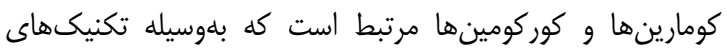

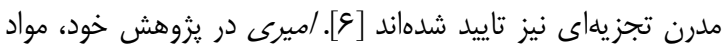

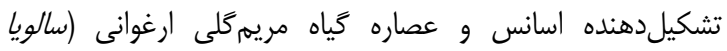

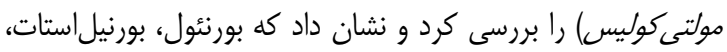

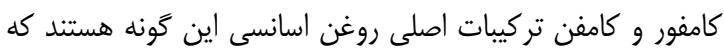
نشان مىدهد مهمترين بخش اين اسانس را تركيبات مونيات مونوترينى تشكيل مىدهند. همجنين بيشترين تركيب موجود در عصاره كياه،

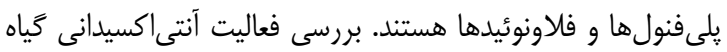

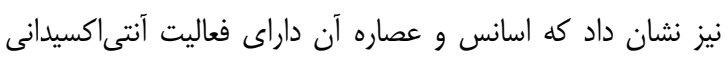

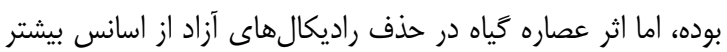

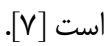

عيدى و همكاران، اثرات ضددردى كَونه ديخرى از جنس سالويا

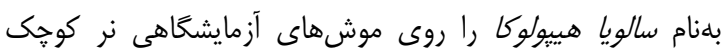

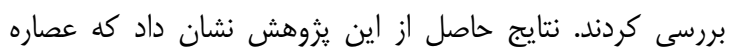

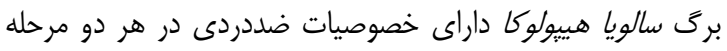

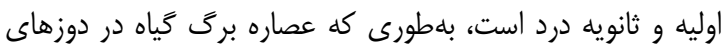

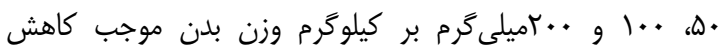
معنى دار در ياسخهاى ظاهرشده در فاز اوليه درد القايى توسط آز آمون فرمالين شد. همجنين عصاره توانست همانند مورفين فاز اوليه درد

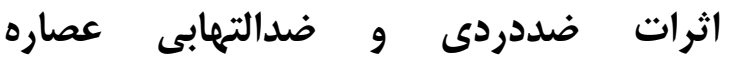

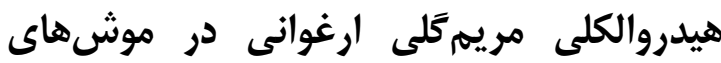

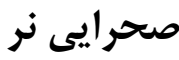

آرش عبدالملكى MSc

كروه زيستشناسى، دانشكده علوم، دانشكاه فردوسى مشهر، مشهل، ايران

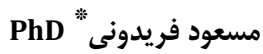

كروه زيستشناسى، دانشكده علوم، دانشكاه فردوسى مشهل، مشهد، ايران

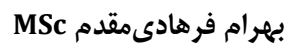

كَروه زيستشناسى، دانشكده علوم، دانشكاه فردوسى مشهل، مشهره، ايران

اشكان عسكَرى MSc

كروه زراعت، دانشكده كشاورزى، دانشخاه فردوسى مشهد، مشهد، ايران

جִكيده

اهداف: يكى از ابتدايىترين روشها براى مقابله با بيمارىها و وتسكين

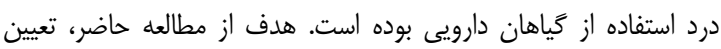

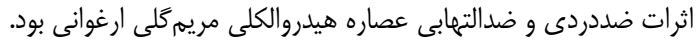

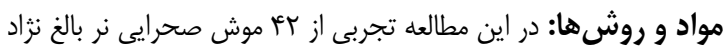

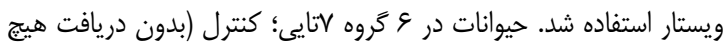

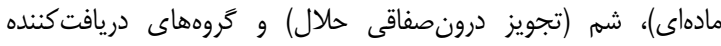

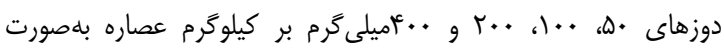

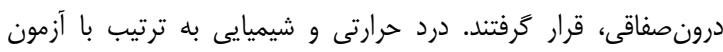

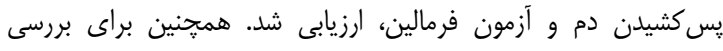

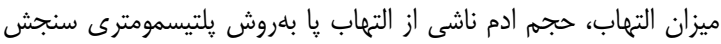

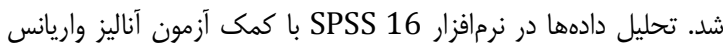

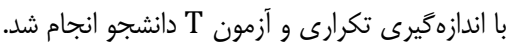

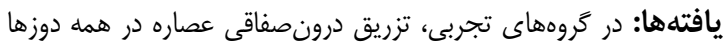

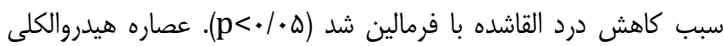

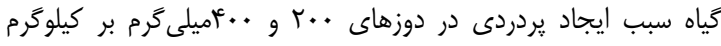

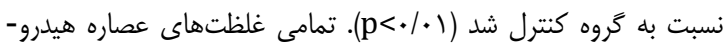

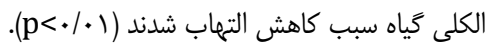
نتيجلَّيرى: تجويز درون صفاقى عصاره هيدروالكلى مريمَّلى ارغوانى النى

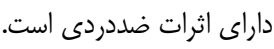
كليدوازهها: موش صحرايى، التهاب، درد، ضددرد، بررسى أنى

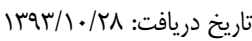

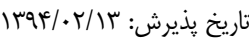

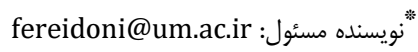

مقدمه

درد تجربه حسى و روحى ناخوشايندى است كه اغلب بهعلت محرك شديد يا آسيبرسان ايجاد مىشود. درد مانند ساير حواس ناسئ

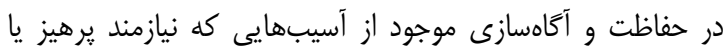

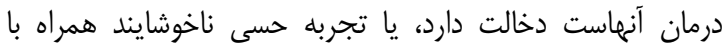




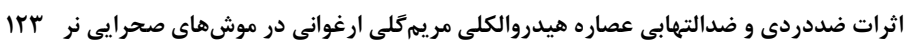

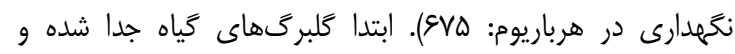

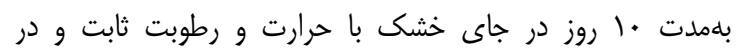

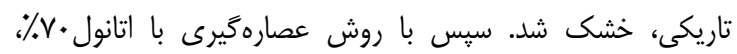

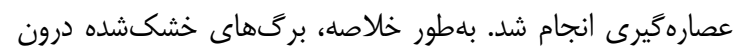

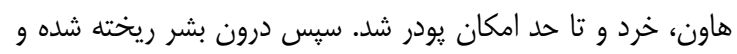

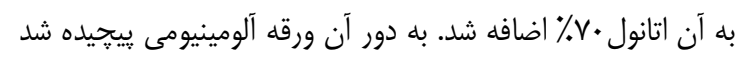

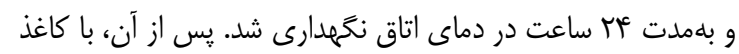

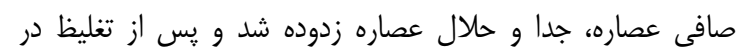

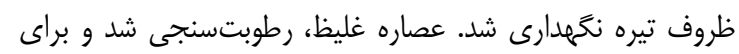

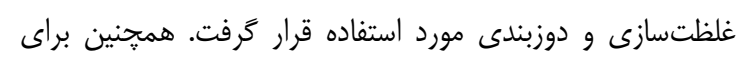
اطمينان از ايمنبودن دوزهاى مورد استفاده، ابتدا سميت عصاره

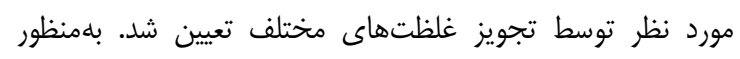

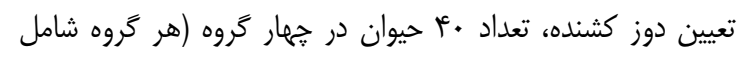

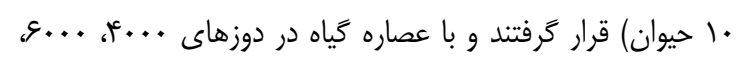

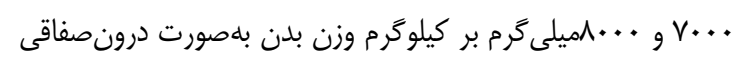

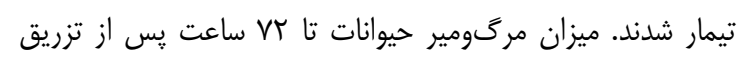

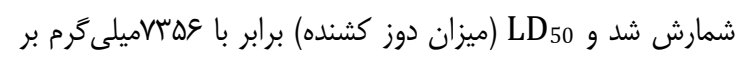
كيلوزرم براى عصاره گياه تعيين شد. شئ

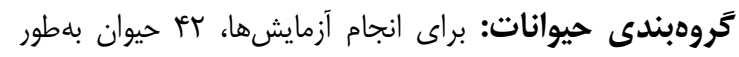
تصادفى در \& گروه لاتايى به ترتيب شامل؛ گروه كنترل (هيج مادها

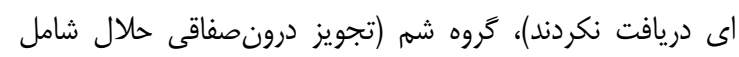

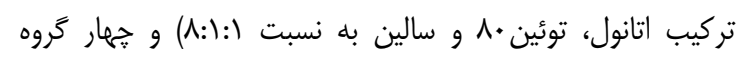

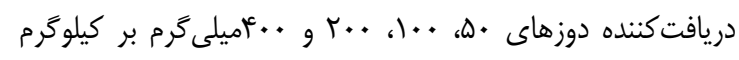

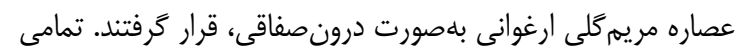

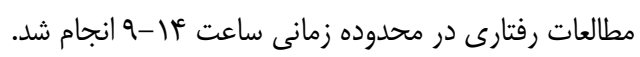
سنجش درد شيميايى: براى سنجش درد شيميايى از آزمون

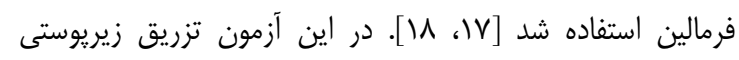

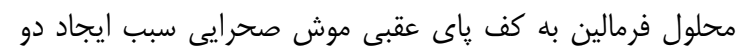

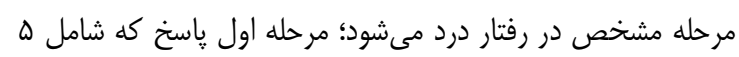
دقيقه اوليه يس از تزريق فرمالين (فاز نوروزنيك) است و مر مرحله

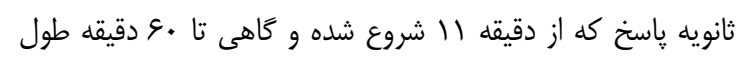

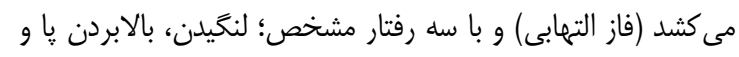

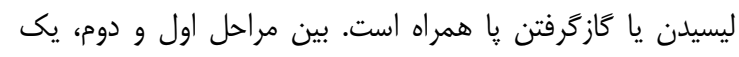

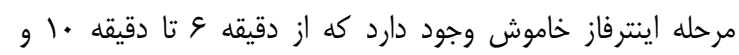

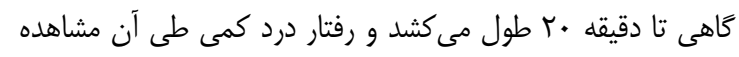

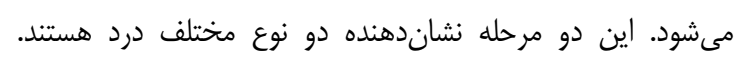
مرحله اول دردى است كه توسط تحريك شيميايى مستقيم اعصاب آوران C توسط فرمالين ايجاد شده است و مرحله دوم، درد القاشده تحسي توسط واكنش التهابى در بافتهاى محيطى است [19].

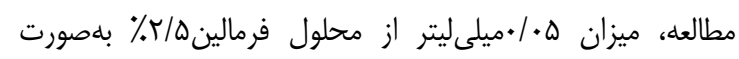
زيرجلدى به كف ياى عقبى حيوان تزريق شد و رفتار حيوان بلمدات

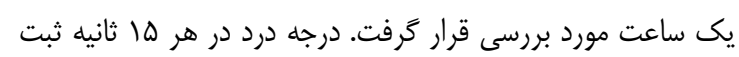

القاشده توسط آزمون فرمالين را بلهورت معنىدار كاهش دهد. در

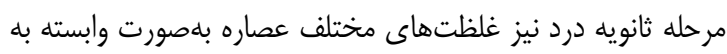

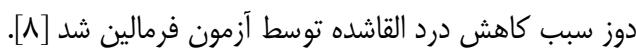
در :ثروشى كه توسط عزيزى و همكاران انجام شد، مواد

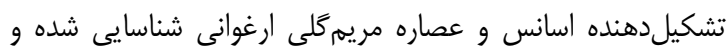
اثرات ضدباكتريايى آن بررسى شد. طبق نتايج اين يثوهش، فعاليت

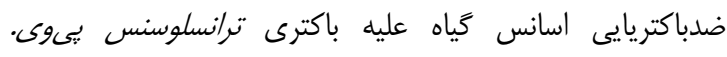

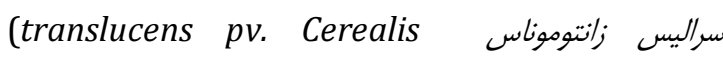
مanthomonas)

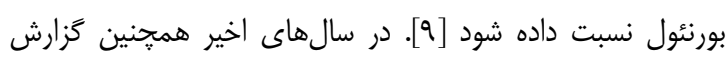
شده است كه اسانس مريم گلى، بهخصوص برخى از تركيبات موجود

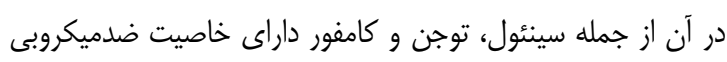
و ضدسرطان است [• (1، 11] جنس سالويا متعلق به تيره نعناع بوده و شامل گياهان علفى و و بوتهاى است كه بلطور وسيعى بلويثه در مناطق معتدل و رَّرم

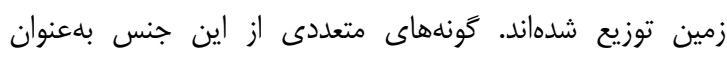
كياهان معطر و زينتى يا بهخاطر فعاليتهاى زيستى آنها مورد

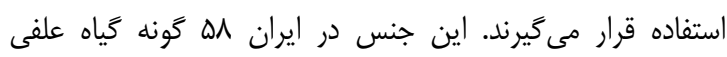

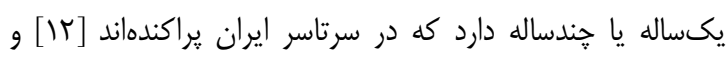

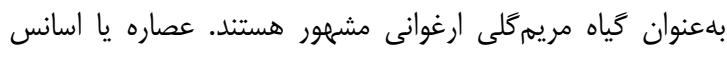

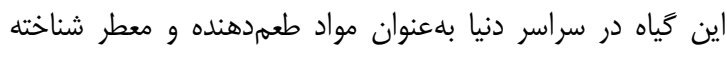

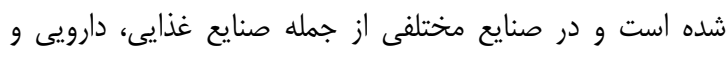

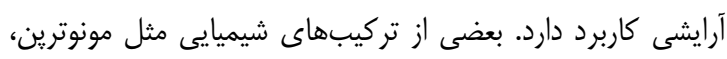

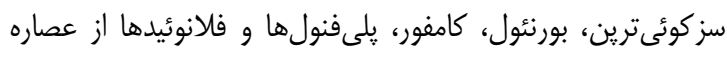

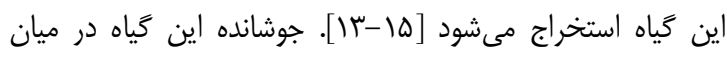

مردم بومى در تسكين درد و التهاب مورد استفاده قرار مى گئيرد.

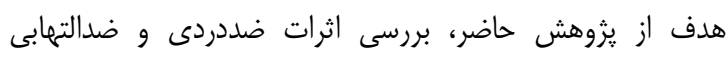

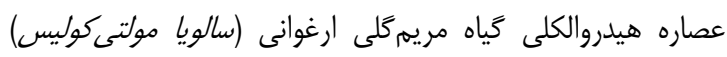
روى موش هاى صحرايى بود.

\section{مواد و روشها}

در اين مطالعه تجربى، از موشهاى صحرايى با سن تقريبى r ماه

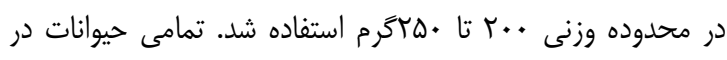
شرايط يكسان محيطى Ir ساعت روشنايى و Ir آ ساعت تاريكى و دماى شّ ${ }^{\circ} \mathrm{C}$ آب و غذا نداشتند. تكثير و يرورش حيوانات در حيوانخانه و انجام كليه آزمايشها در آزمايشگاه تحقيقاتى فيزيولوزى جانورى دئن دانشعاه

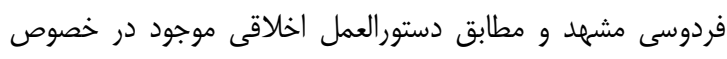

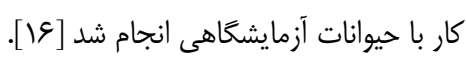

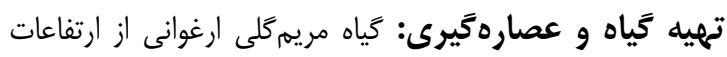

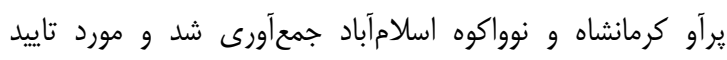
هرباريوم دانشخاه فردوسى مشهد قرار گرفت (شماره شناسايى و وانى 
مقايسه بين گروهها، نتايج بلصورت درصد حداكثر اثر ممكن (MPE\%)

سنجش ميزان التهاب: براى سنجش ميزان التهاب، از اندازهگيرى حجم ادم يا ناشى از التهاب استفاده شد. ابتدا حجم اوليه ياى حيوان بلروش يلتيسمومترى ديجيتالى اندازهيرى شد. در اين

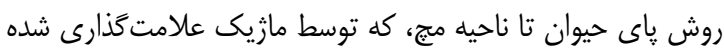
بود، به درون ستون جيوهاى كه روى ترازوى ديجيتالى قرار گرفته،

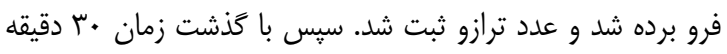

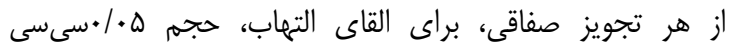

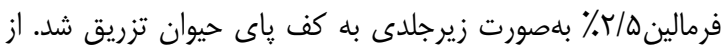
آنجا كه بعد از كذشت •و دقيقه از تزريق فرمالين، ميزان التهاب

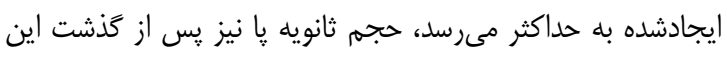

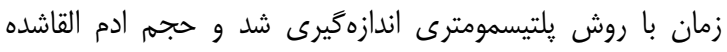

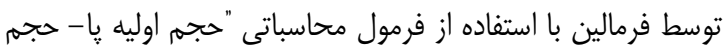

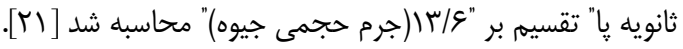

شد. سيس ميانگين درجههاى درد در هر ه دقيقه محاسبه شد. درجلبندى درد در اين آزمون بهصورت زير بود: عدد صفر براى دياى

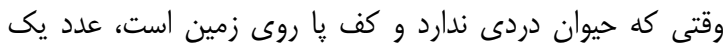

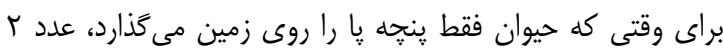

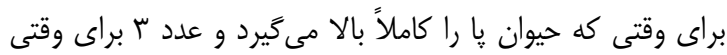

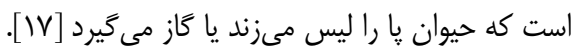
سنجش درد حرارتى: براى سنجش درد حرارتى از آزمون

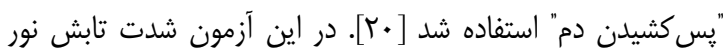

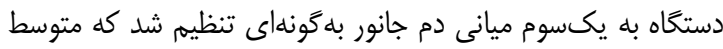

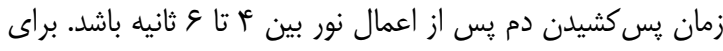

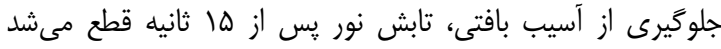

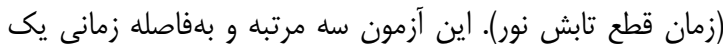

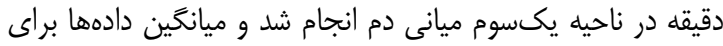

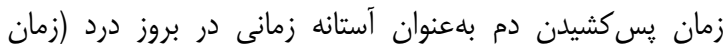

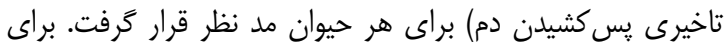
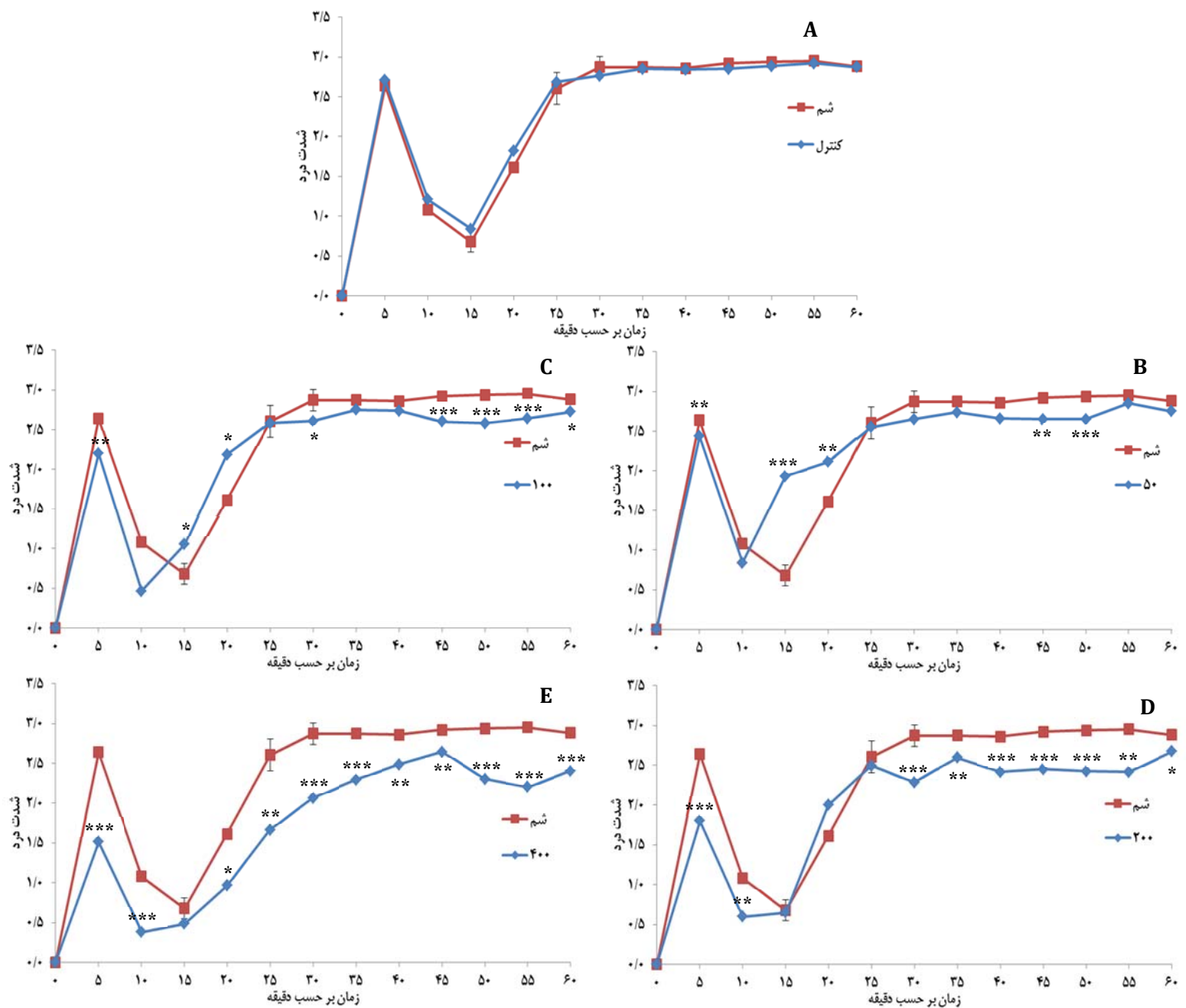

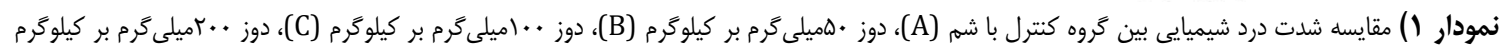

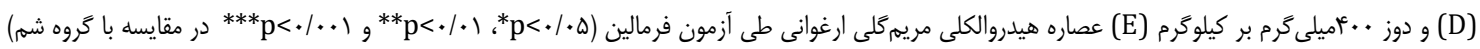




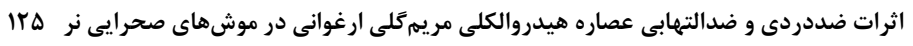

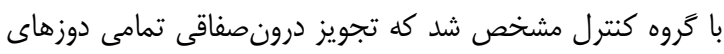

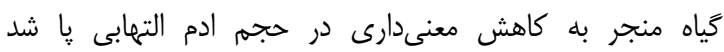

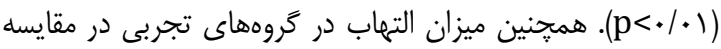

با كَروه كنترل با افزايش دوز نسبت معكوس داشت (نمودار بَ).

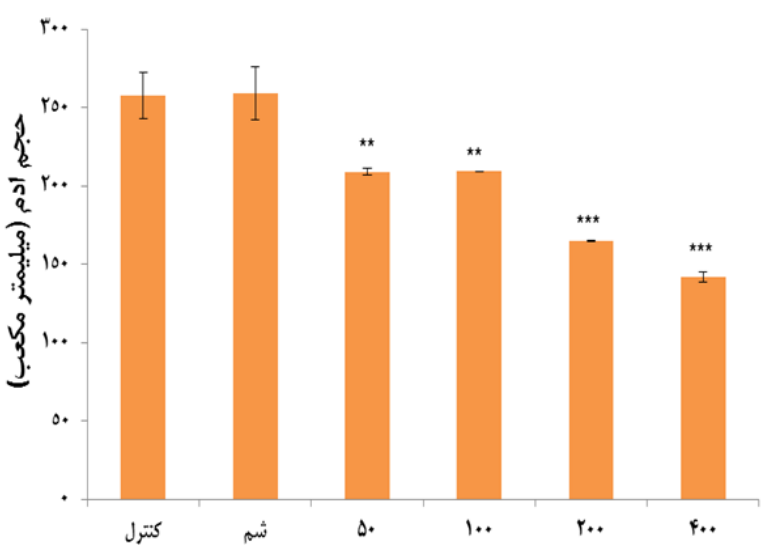

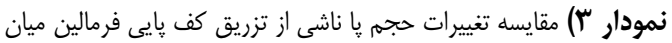

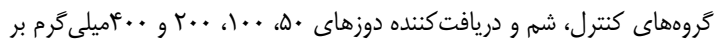

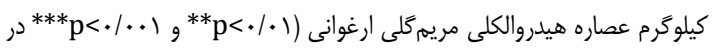
مقايسه با كروه شم) (انمان/

مقايسه تغييرات حجم پإ ناشى از تزريق كفيايى فرمالين بين

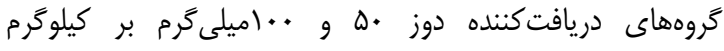

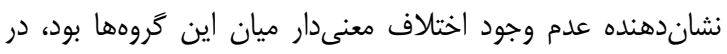

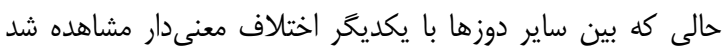

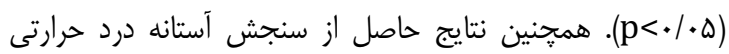

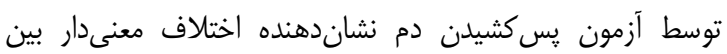

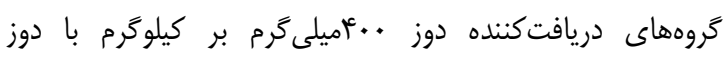

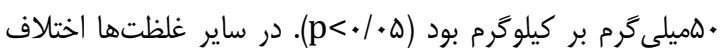

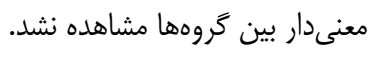

در اين تحقيق ابتدا سميت عصاره مورد نظر براى اطمينان از

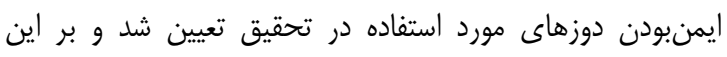

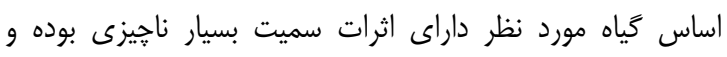

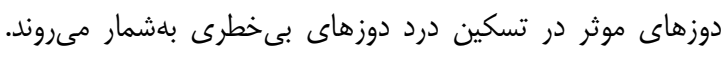

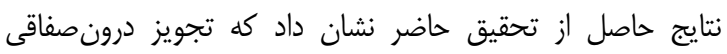

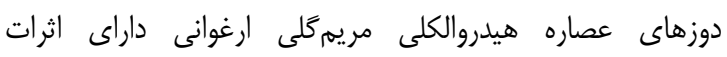

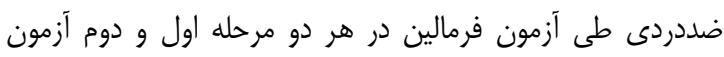

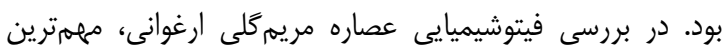

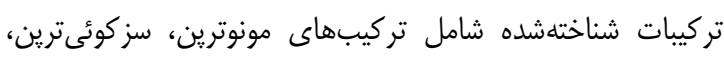

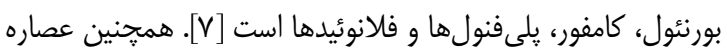

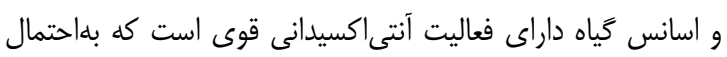

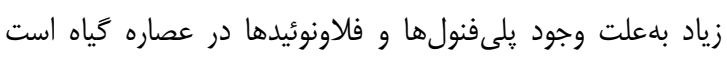

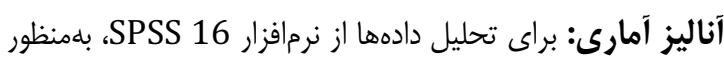

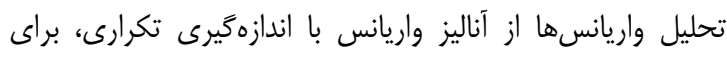

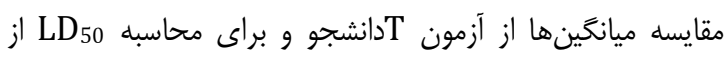

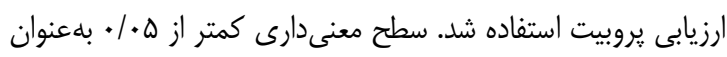
مرز استنتاج آمارى قرار داده شد.

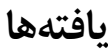

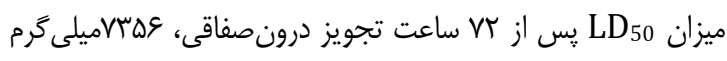

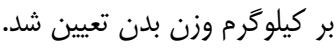

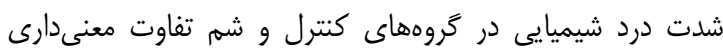

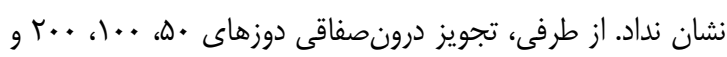

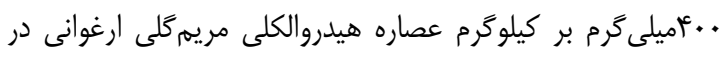

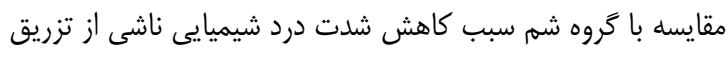

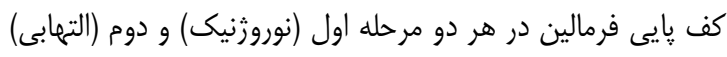

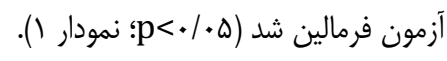

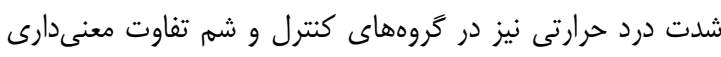

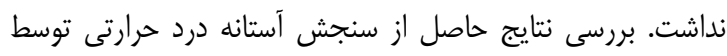

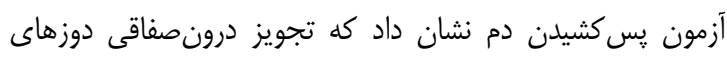

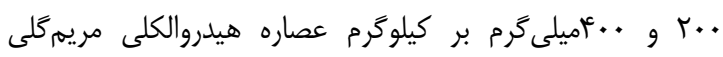

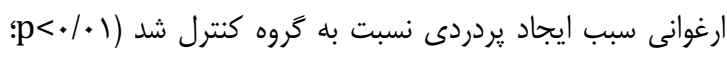

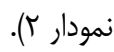

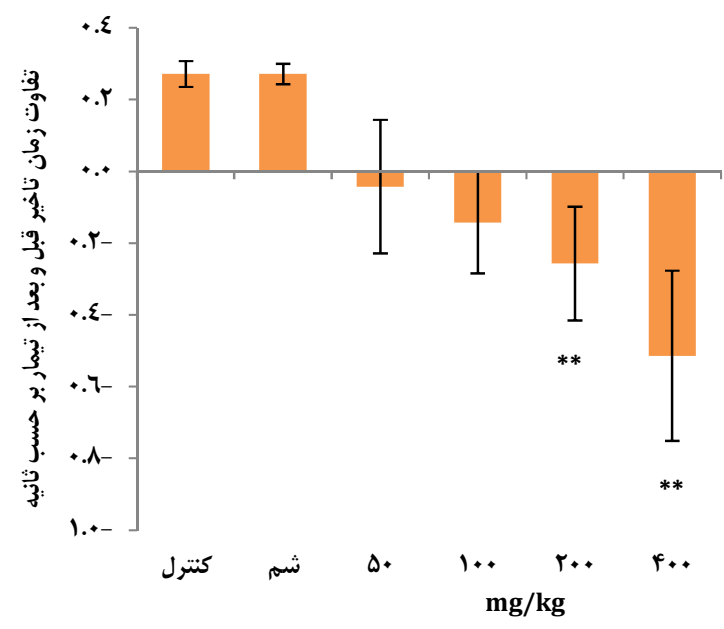

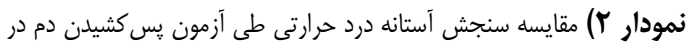

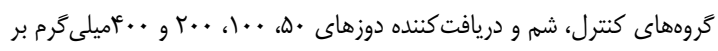

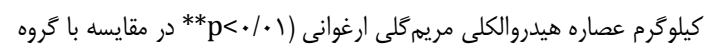

شهم)

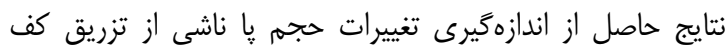

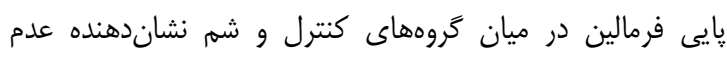

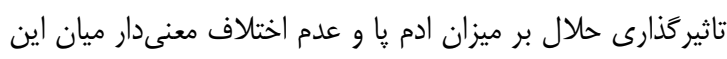

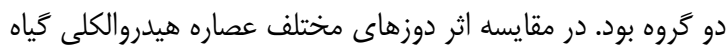


ساير مطالعات نشان مىدهند كه فلاونوئيدها با مهار فعاليت

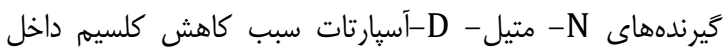

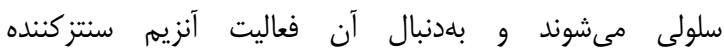

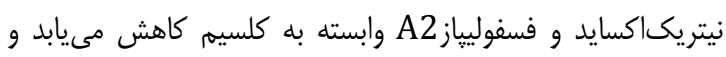

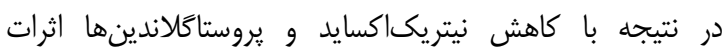

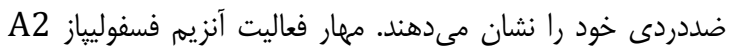

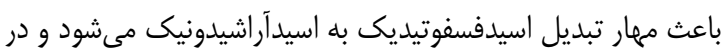

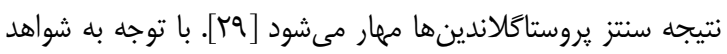

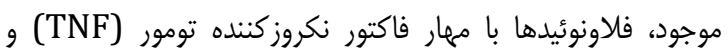

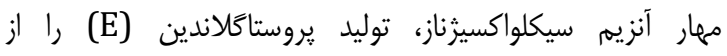

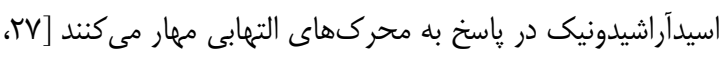

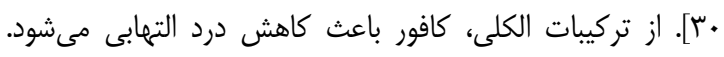

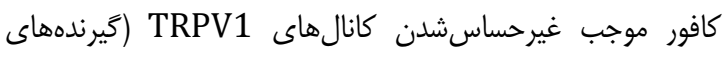

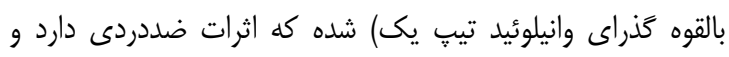

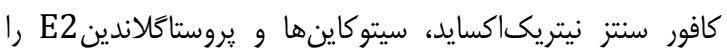

مهار مى كند. همجنين سبب مهار آزادسازى كلسيم مى شود [ (بس].

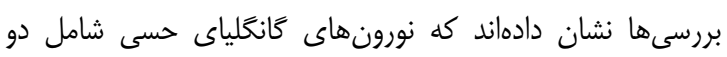

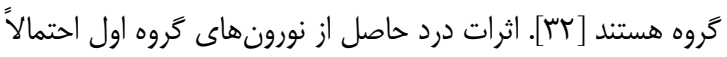

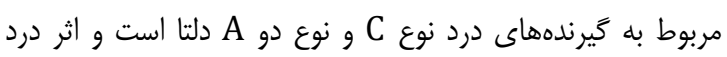

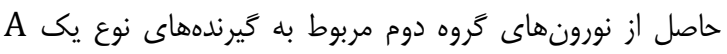

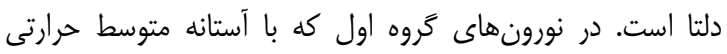

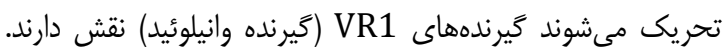

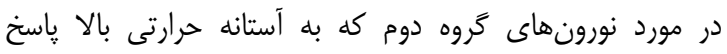

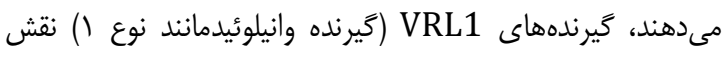

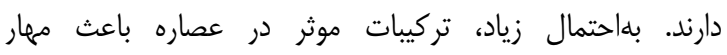

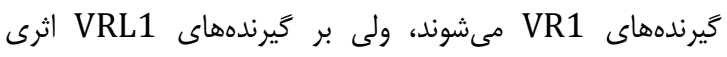

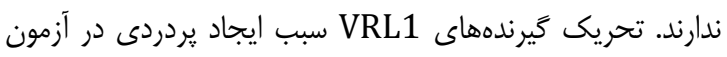
درد حرارتى شده است [بسـ].

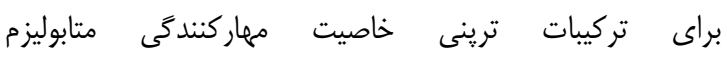

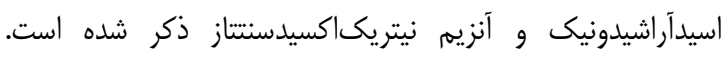

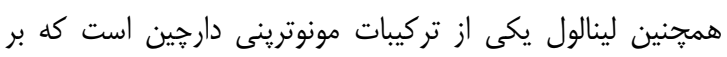

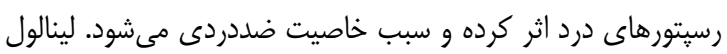

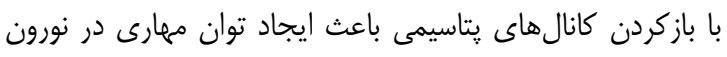

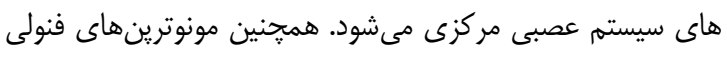

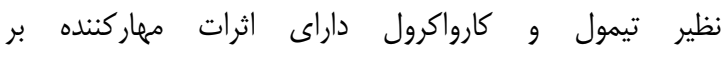

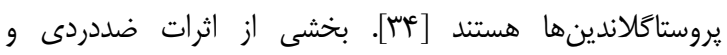

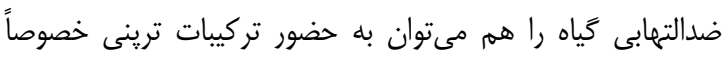

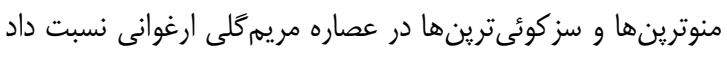

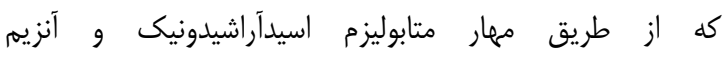

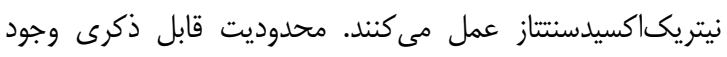

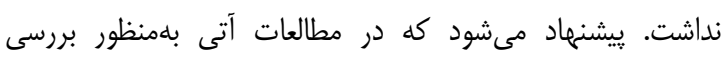

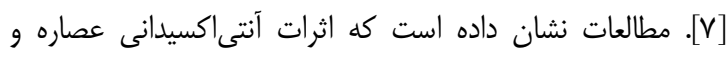

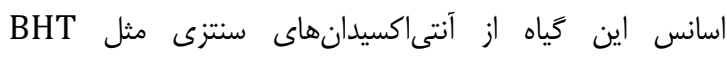

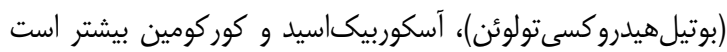

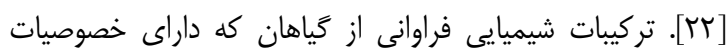

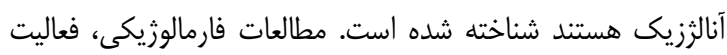

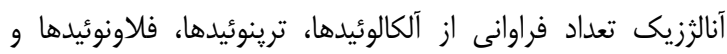

$$
\text { لاكتونها را اثبات نموده است [ــ]. }
$$

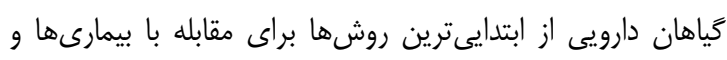

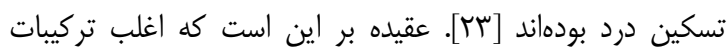

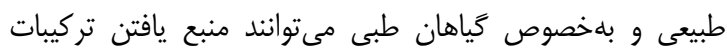

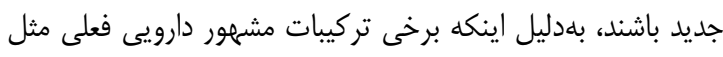

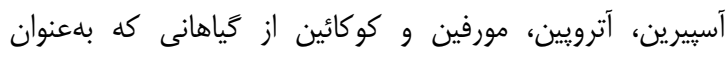

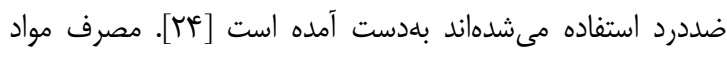

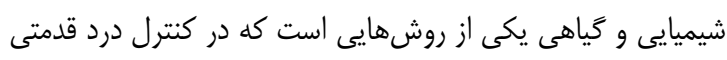

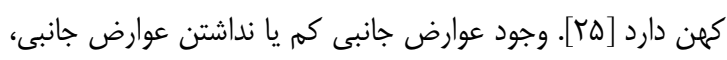

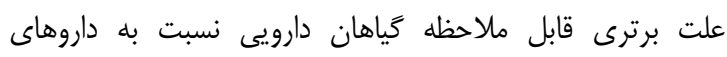

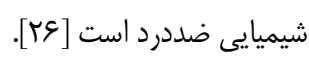

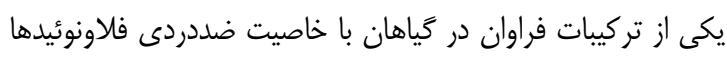

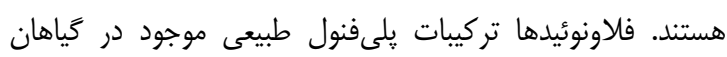

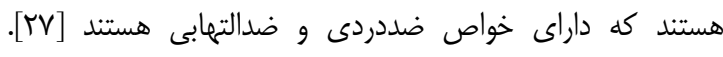

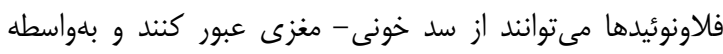

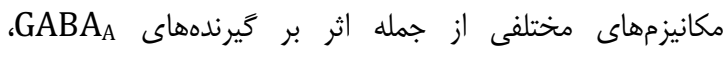

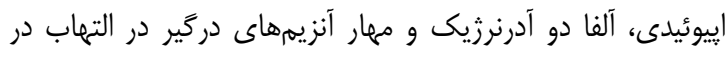

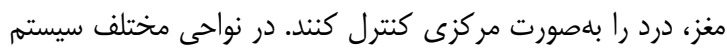

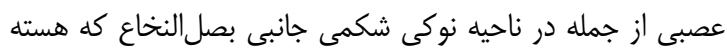

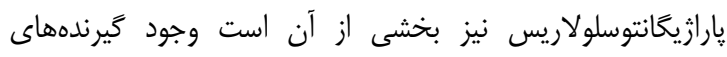

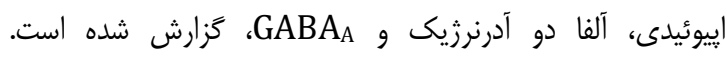

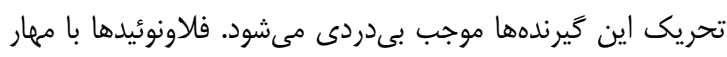

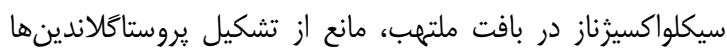

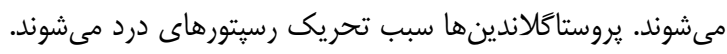

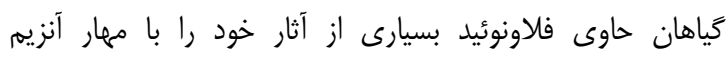

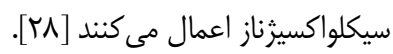

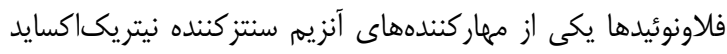

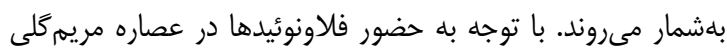

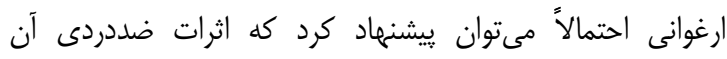

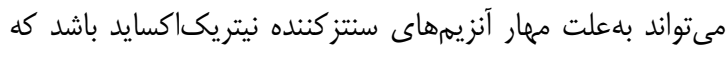

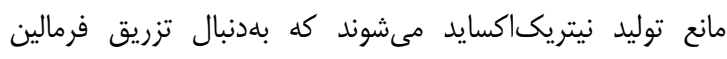

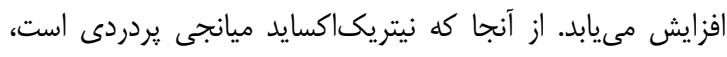

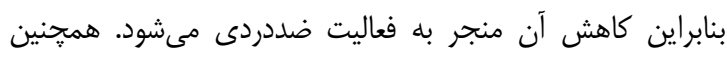

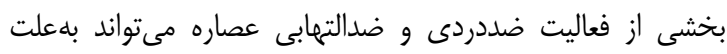

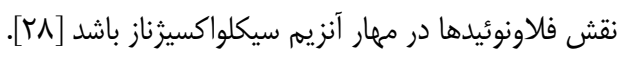




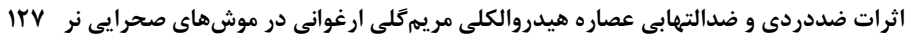

composition of sage oil. J Essen Oil Res. 1997;9(2):18791.

12- Mancini E, Arnold NA, De Martino L, De Feo V, Formisano C, Rigano D, et al. Chemical composition and phytotoxic effects of essential oils of Salvia hierosolymitana boiss. and Salvia multicaulis vahl. var. Simplicifolia boiss. growing wild in Lebanon. Molecules. 2009;14(11):4725-36.

13- Ulubelen A, Topcu G. Salvimultine, a new noricetexane diterpene from the roots of Salvia multicaulis. J Nat Prod. 2000;63(6):879-80.

14- Şahin F, Güllüce M, Daferera D, Sökmen A, Sökmen M, Polissiou M, et al. Biological activities of the essential oils and methanol extract of Origanum vulgare ssp. vulgare in the Eastern Anatolia region of Turkey. Food Control. 2004;15(7):549-57.

15- Adams RP. Identification of essential oil components by gas chromatography/mass spectroscopy. J Am Soc Mass Spectrom. 1997;6(8):671-2.

16- Zimmermann M. Ethical considerations in relation to pain in animal experimentation. Acta Physiol Scand Suppl. 1986;554:221-33.

17- Dubuisson D, Dennis SG. The formalin test: A quantitative study of the analgesic effects of morphine, meperidine, and brain stem stimulation in rats and cats. Pain. 1977;4(2):161-74.

18- Heidari Oranjaghi N, Azhdari Zarmehri H, Erami E, Haghparast A. Antagonism of orexin-1 receptors attenuates swim-and restraint stress-induced antinociceptive behaviors in formalin test. Pharmacol Biochem Behav. 2012;103(2):299-307.

19- Randolph BC, Peters MA. Analgesic effectiveness of ketorolac compared to meperidine in the rat formalin test. Anesth Prog. 1997;44(1):11-6.

20- D'amour FE, Smith DL. A method for determining loss of pain sensation. J Pharmacol Exp Ther. 1941;72(1):74-9.

21- Fereidoni M, Ahmadiani A, Semnanian S, Javan M. An accurate and simple method for measurement of paw edema. J Pharmacol Toxicol Methods. 2000;43(1):11-4.

22- Tepe B, Donmez E, Unlu M, Candan F, Daferera D, Vardar-Unlu G, et al. Antimicrobial and antioxidative activities of the essential oils and methanol extracts of Salvia cryptantha (Montbret et Aucher ex Benth.) and Salvia multicaulis (Vahl). Food Chem. 2004;84(4):51925.

23- Heidari MR, Vahedian M, Moamenzadeh S, Hayatbakhsh Abbasi MM. The analgesic effect and possible mechanism of colchicum szovitsii methanolic extract in mouse. J Rafsanjan Univ Med Sci. 2005;4(1):25-33. [Persian]

24- Verdi J, Kamalinezhad M, Sabet Kasaei M, Sharif SH. Analgesic Effect Of Aqueous Satureja Hortensis L. Seed Extract In Male Rat. Physiol Pharmacol J. 2004;8(2):1638. [Persian]

25- Vaez G, Tavasoli Z, Ranjbar Bahadori S. Study on the different dosages of Elaeagnus angustifolia aqueous extract with and without morphine on the antinociceptive rate in mice. Pejouhesh. 2011;35(1):2733. [Persian]

26- Taherian AA, Etemadi H, Sadeghi H. Assessment of aqueous extract of seed of Cuminum cyminum L. on neurogenic and inflammatory pain in mice. JMP. 2007;4(24):44-50. [Persian]

27- Parveen Z, Yulin D, Muhammad KS, Rongji D, Waqar A, Yu Hong Y. Antiinflammatory and analgesic activities of Thesium chinense Turcz extracts and its major

$$
\begin{aligned}
& \text { مكانيسم دقيق اين عصاره از آنتاكونيست و آكَنيستهاى گيرنده } \\
& \text { VRL-1 }
\end{aligned}
$$

$$
\begin{aligned}
& \text { نتيجه كَيرى } \\
& \text { تجويز درونصفاقى عصاره هيدروالكلى مريمثلى ارغوانى داراى } \\
& \text { اثرات ضددردى است، بلطورى كه سبب كاهش شدت درون درد شيميايى } \\
& \text { در آزمون فرمالين مىشود. }
\end{aligned}
$$

تشكر و قدردانى: بدين وسيله از معاونت يزوهشى دانشگاه فردوسى مشهد تقدير و تشكر مىشود.

تاييديه اخلاقى: انجام كليه آزمايشها در آزمايشگاه تحقيقاتى فيزيولوزى جانورى دانشخاه فردوسى مشهر مطابق دستورالعمل اخلاقى موجود در خصوص كار با حيوانات آزمايشگاهى انجام شد. تعارض منافع: موردى توسط نويسندكان اعلام نشده است. منابع مالى: توسط دانشگاه فردوسى مشهد تامين شده است. توسط نويسن

\section{منابع}

1- Walsh DA, Mc Williams DF. Mechanisms, impact and management of pain in rheumatoid arthritis. Nat Rev Rheumatol. 2014;10(10):581-92.

2- Bahmani M, Shirzad H, Majlesi M, Shahinfard N, Rafieian Kopaei M. A review study on analgesic applications of Iranian medicinal plants. Asian Pac J Trop Med. 2014;7S1:S43-53.

3- De Melo MS, Quintans JJS, Araújo AAS, Duarte MC, Bonjardim LR, Nogueira PCL, et al. A systematic review for anti-inflammatory property of clusiaceae family: A preclinical approach. Evid Based Complement Alternat Med. 2014;960258.

4- Cash JL, Norling LV, Perretti M. Resolution of inflammation: Targeting GPCRs that interact with lipids and peptides. Drug Discov Today. 2014;19(8):1186-92.

5- Nishimoto N, Kishimoto T. Interleukin 6: From bench to bedside. Nat Clin Pract Rheumatol. 2006;2(11):61926.

6- Saeed MK, Deng Y, Dai R, Li W, Yu Y, Iqbal Z. Appraisal of antinociceptive and anti-inflammatory potential of extract and fractions from the leaves of Torreya grandis Fort Ex. J Ethnopharmacol. 2010;127(2):414-8.

7- Amiri H. Chemical composition and antioxidant activity of the essential oil and methanolic extract of Salvia multicaulis Vahl. JMP. 2012;1(41):111-7. [Persian] 8- Eidi A, Parivar K, Mazouji A, Akhtari Z. Antinociceptive effects of essential oil of Salvia hypoleuca L. in mice. Med Sci J Islamic Azad Univ. 2006;16(3):165-9. [Persian] 9- Azizi A, Azizi AM, Azizi G. Essential oils composition and antimicrobal effects of essential oils and methanol extracts of Salvia multicaulis. Vahl against Xanthomonas translucens pv. Cerealis. J Plant Sci Res. 2009;15(3):3948.

10- Carta C, Morettib DLM, Peana AT. Activity of the oil of Salvia officinalis L. against Botrytis cinerea. J Essen Oil Res. 1996;8(4):399-404.

11- Piccaglia R, Marotti M, Dellacecca V. Effect of planting density and harvest date on yield and chemical 
31- Morshedi A, Dashti MH, Dehghan HM, Bagherinasab MA, Salami AS. The effect of Artemisia sieberi Besser on inflammatory and neurogenic pain in mice. JMP. 2011;4(40):48-57. [Persian]

32- Nagy I, Rang H. Noxious heat activates all capsaicinsensitive and also a sub-population of capsaicininsensitive dorsal root ganglion neurons. Neuroscience. 1999;88(4):995-7.

33- Julius D, Basbaum AI. Molecular mechanisms of nociception. Nature. 2001;413(6852):203-10.

34- Pahlavan Y, Sepehri GR, Afarinesh Khaki MR, Sheibani V, Esmail Pour K, Pahlavan B. Intervention of morphine and naloxone on analgesic effects of origanum vulgare extract in male rat. J Ardabil Univ Med Sci. 2011;11(2):134-42. [Persian]
1 آ آرش عبدالملكى و همكاران

flavonoids, kaempferol and kaempferol-3-0-glucoside. Yakugaku Zasshi. 2007;127(8):1275-9.

28- Hoodgar F, Nasri S, Amin GHR. Investigation of antinociceptive and anti-inflammatory effects of hydroalcoholic extract of Securigera securidaca L. Horizon Med Sci. 2011;17(2):12-9. [Persian]

29- Alibabaei Z, Pilehvarian AA, Shirani M, Kheiri S, Taji F, Asgari A, et al. Effect of Euphorbia helioscopia on acetic acid-induced abdominal constrictions in Balb/c mice. J Shahrekord Univ Med Sci. 2010;11(4):9-14. [Persian]

30- Dashti Rahmatabadi MH, Vahidi Mehrjardi AR, Pilavaran AA, Farzan F. Antinociceptive effect of cinnamon extract on formalin induced pain in rat. JSSU. 2009;17(2):190-9. [Persian] 